\title{
Segregation of an insertional chromosome rearrangement in 3 generations
}

\author{
K. E. TOOMEY ${ }^{1}$, T. MOHANDAS, R. S. SPARKES, M. M. KABACK, AND \\ D. L. RIMOIN
}

From the Department of Pediatrics, University of South Florida, Tampa, Florida; the Division of Medical Genetics, Harbor General Hospital, UCLA School of Medicine, Torrance, California; and Center for the Healt Sciences, UCLA School of Medicine, Los Angeles, California, USA

SUMMARY The interstitial deletion of a segment of chromosome 13,13q21 $\rightarrow 13 q 22$, and its inversion? and insertion into the long arm of chromosome 3 at breakpoint q12, was found to segregate in generations of a family. Segregation of this 3 break rearrangement gave rise to individuals monosomic trisomic, or balanced for the involved segment. Monosomy for 13q21 $\rightarrow 13 q 22$ was associated with mental retardation, expressive aphasia, microcephaly; hand abnormalities, and short stature. Partially trisomic individuals had normal mentality, extremely high arched palate, and mild dysmorphi导 features. There was no evidence for retinoblastoma in the individuals examined. The balanced carrier: were normal. Comparison of monosomic individuals with one previous report of a similar deletion reveals marked phenotypic similarities.

The interstitial deletion of a segment from a chromosome and its insertion into another chromosome is a rarely observed event in man. However, with the availability of the various chromosome banding procedures, several of these interstitial translocations have been described in recent years (Grace et al., 1972; Gray et al., 1972; Rethoré et al., 1972; Shapiro and Warburton, 1972; Berger et al., 1974; Chudley et al., 1974).

This report summarises the karyotypic and phenotypic features of a family in which such an interstitial rearrangement involving segment q21 $\rightarrow$ q22 of chromosome 13 was detected.

\section{Case reports}

IV. 6 (Fig. 1)

The proband (Fig. 2), a 7-year, 9-month-old white girl, was referred for evaluation of short stature, microcephaly, and expressive aphasia. She was the product of a 33-week gestation, birthweight $2693 \mathrm{~g}$, born to a G2,PO,A1 mother. Labour was preceded by premature rupture of membranes and delivery was in the breech position. No abnormalities were noted at birth. Gross motor and social milestones were passed at slightly delayed ages. Most marked was her delay in

\footnotetext{
'Supported in part by NIH Training Grant HD-00417-05.
} Received for publication 22 December 1977
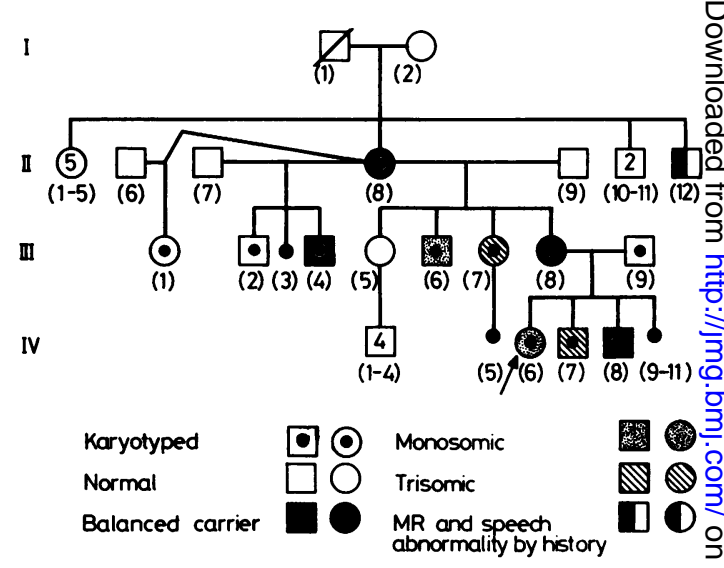

Fig. 1 Pedigree of the family. The presence of individual II.12, who is, by report, mentally retarded and has a speech abnormality, leads us to suspect that this abnormality has of been present for 4 generations.

the development of language skills. Mental age at $\mathbb{\Phi}$ years was 4 years, 9 months, with an IQ of 74 (Leitep Performance Scale). Receptive language was commenf surate with mental age, but expressive language ${ }^{+}$ development was 3 years when tested at 4 years, months. Her hearing was normal. On examination? height, weight, and head circumference were all 4 S\$ 382 


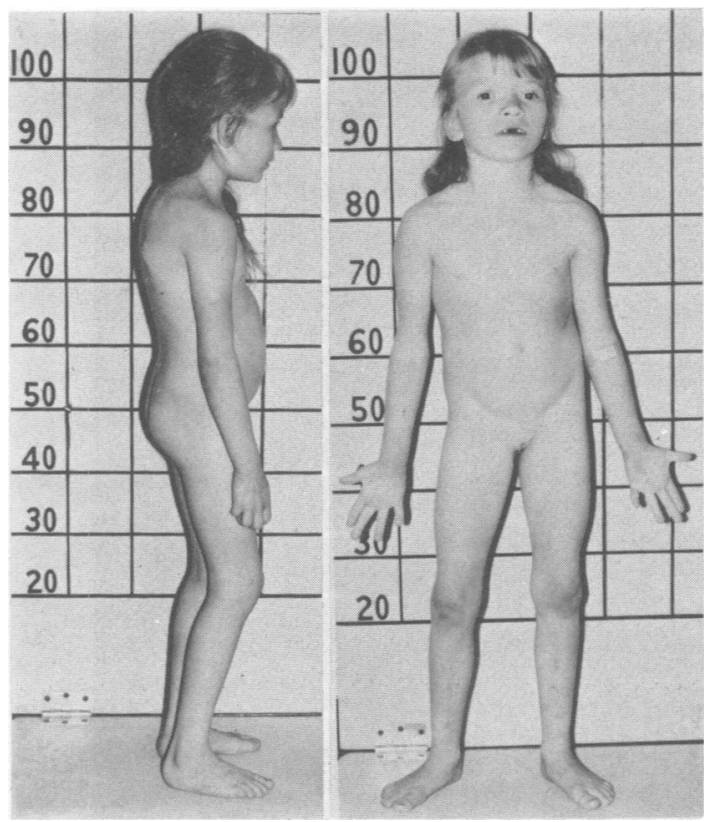

Fig. 2 The proband (IV.6) at age $7 \frac{3}{4}$ years.

below the mean for her age. The facies were unusual with brachycephaly, dystopia canthorum, and bilateral esotropia. She had a wide down-turning mouth with a high arched palate. Fundoscopic examination under anaesthesia was normal. The neck was short, giving a webbed appearance. The ears were normal in size, but appeared large in relation to head size; they were low set and posteriorly rotated. The chest appeared broad and the nipples were widely spaced. The hands were short and broad with single flexion creases of the fifth digits bilaterally. The thumbs were proximally inserted. There were 5 whorls and 5 ulnar loops and a $t^{\prime \prime}$ bilaterally, with radial loops in the hypothenar areas. With the exception of her speech, the neurological examination was normal.

IV.7

A brother of the proband, aged $5 \frac{1}{2}$ years, was of normal mental development (Fig. 3). He was at the 90th, 75th, and 50th centiles for height, weight, and head circumference, respectively. He had unusual facies with mild synophrys, a short nose with anteverted nostrils, and small, low set ears. The neck was short and his palate was highly arched. The hands showed bilateral clinodactyly, bridged simian creases, and 5 whorls and 5 ulnar loops.

\section{8}

A second brother of the proband, aged $3 \frac{1}{2}$ years, was of normal physical and mental development.

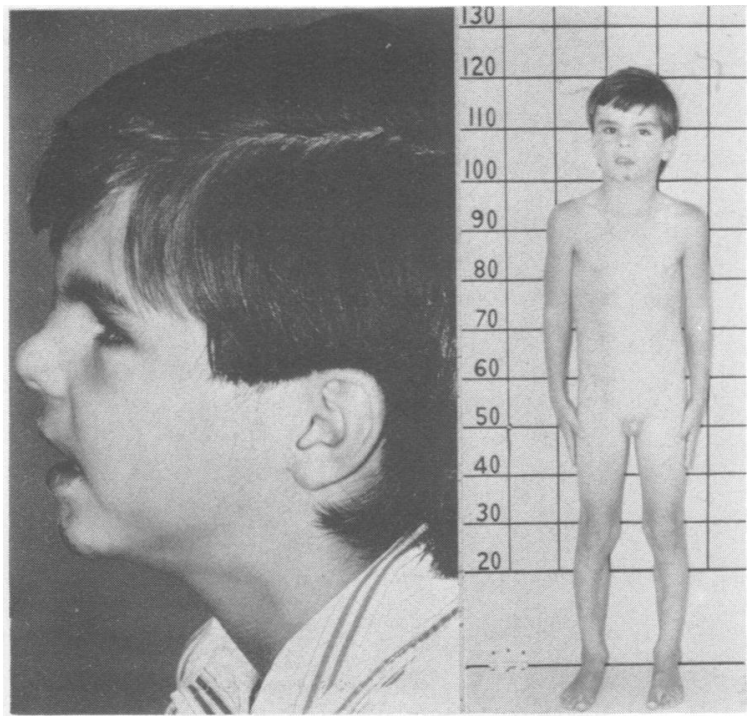

Fig. 3 Brother of the proband (IV.7), at age $5 \frac{1}{2}$ years.

III. 7

A maternal aunt of the proband, aged 26, was of normal intelligence. She had one spontaneous abortion at $\mathbf{2}$ to $\mathbf{3}$ months' gestation, about which nothing more is known. Physical examination was unremarkable, with the exception of an extremely highly arched palate which required a prosthetic palatal shelf to effect normal articulation.

\section{III.6}

A full brother of the proband's mother was institutionalised in another state, and was unavailable for detailed examination. He carried a diagnosis of mental retardation and microcephaly with particularly delayed language skills. Pictures taken of him at 26 years of age and available data revealed: height 155 $\mathrm{cm}$, weight $45.36 \mathrm{~kg}$. No head circumference was recorded. The head appeared small and the neck was short with a webbed appearance. The ears were low set and posteriorly rotated. The nasal bridge appeared broad and flat. The thumbs were proximally inserted. His expressive vocabulary consisted of 5 words, and he followed a few simple directions. Hearing was normal.

\section{12}

A maternal uncle of the proband's mother, aged 45, lived with his mother. He was mentally retarded and had a speech abnormality by history. Pictures showed him to have a broad down-turning mouth, low set posteriorly rotated ears, and a narrow forehead.

The mother (III.8), maternal grandmother (II.8), as well as 3 other children of the maternal grandmother (III.1, III.2, and III.4), were all normal. 


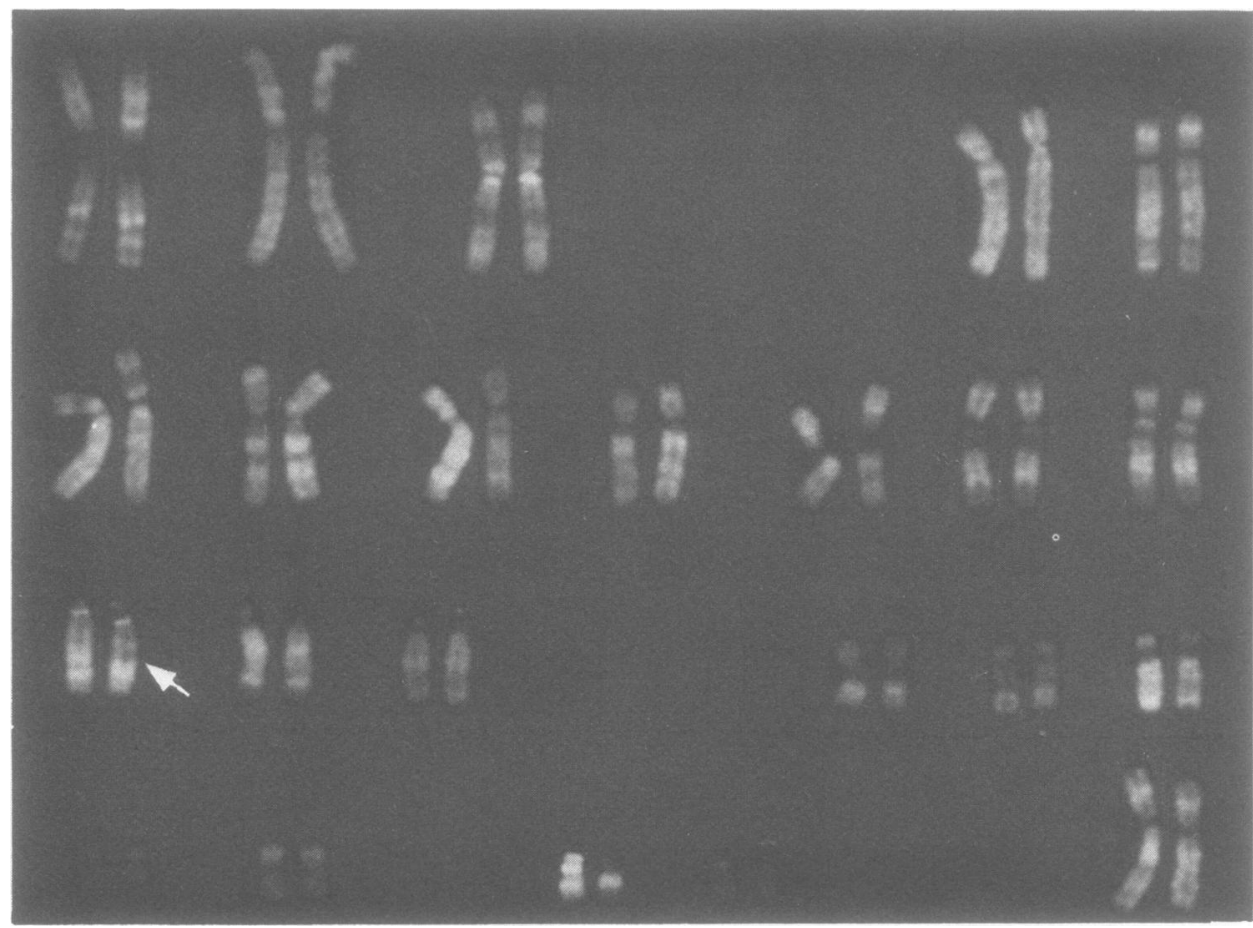

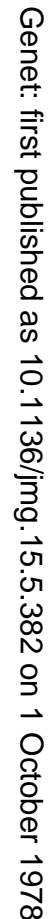

Fig. 4 Karyotype of proband (IV.6), 46, XX, der (13), inv. ins. $(3 ; 13)(q 12: q 22 q 21)$ mat. Arrow designates deleted band of chromosome 13.

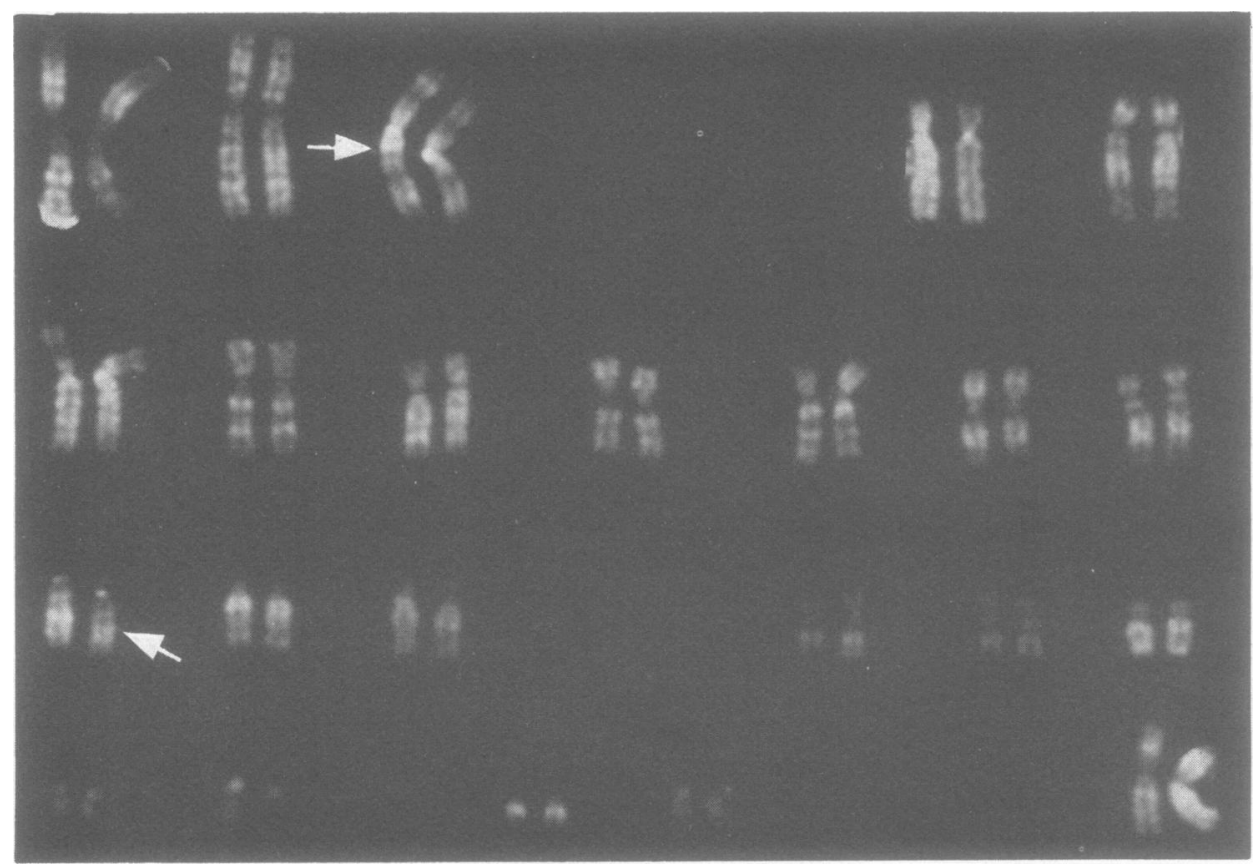

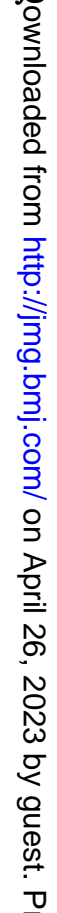

Fig. 5 Karyotype of proband's mother (III.8), 46, XX, inv. ins. (3; 13) (q12:q22q21). Arrows indicate additional bright $\stackrel{\vec{\circ}}{\circ}$ band on chromosome 3 and deleted band of chromosome 13. 


\section{Cytogenetic studies}

Chromosome analysis on available family members was performed on phytohaemagglutinin stimulated peripheral blood cultures with the aid of Q-banding (Caspersson et al., 1970). The proband's karyotype was found to be 46,AA with monosomy for the segment q21 $\rightarrow$ q22 of chromosome 13 resulting from an interstitial deletion (Fig. 4). Examination of the mother's karyotype (Fig. 5) showed the same interstitial deletion on one of her no. 13 chromosomes; in addition she had an elongation of the long arm of chromosome 3, because of the presence of an additional bright band just below and clearly separable from the bright polymorphic band. Closer examination showed this additional band on chromosome 3 to be the deleted segment of 13 , inverted and inserted at point 3q12. Thus, the mother was a balanced carrier of a nonreciprocal interstitial translocation. A schematic diagram of the rearrangement is presented in Fig. 7. The proband's karyotype also showed bright and prominent short arms and satellites on one of her no. 21 chromosomes (Fig. 4), which was found to be inherited from her father (Fig. 6). Analysis of the father's chromosomes showed a normal karyotype. The maternal grandmother (II.8) and a normal younger brother of the proband (IV.8) were balanced carriers of the rearrangement. One of the proband's brothers (IV.7) and a maternal aunt (III.7) were trisomic for the q21 $\rightarrow$ q22 segment of chromosome 13. The maternal uncle (III.6) of the proband was found to be monosomic, as expected on clinical grounds. The chromosome findings are summarised in Fig. 1. A composite of partial karyotypes (Fig. 6) shows a comparison of chromosomes 3,13 , and 21 in individuals III.8, III.9, IV.6, and IV.7. Twenty-four well-described genetic markers (red cell enzymes, serum proteins, and red cell antigens) were evaluated in all the individuals who were karyotyped in this family for possible linkage data, but the results were uninformative.

\section{Discussion}

Interstitial nonreciprocal translocations resulting from 3 break chromosome rearrangements are rare in the human population. In the present family, such a rearrangement between chromosomes 3 and 13 is shown to segregate in 3 generations. The break points on chromosome 13 (Fig. 7) are just above band q31 and in band $\mathrm{q} 21$. In routine $\mathrm{Q}$-banded preparations, in our hands, the light band q22 on chromosome 13 is wider, in relation to bands $\mathrm{q} 21$ and $\mathrm{q} 31$, than that shown in the Paris Conference (1971) diagram. Band q21 of chromosome 13 in well-banded preparations is seen to consist of 2 bands, the more proximal of which

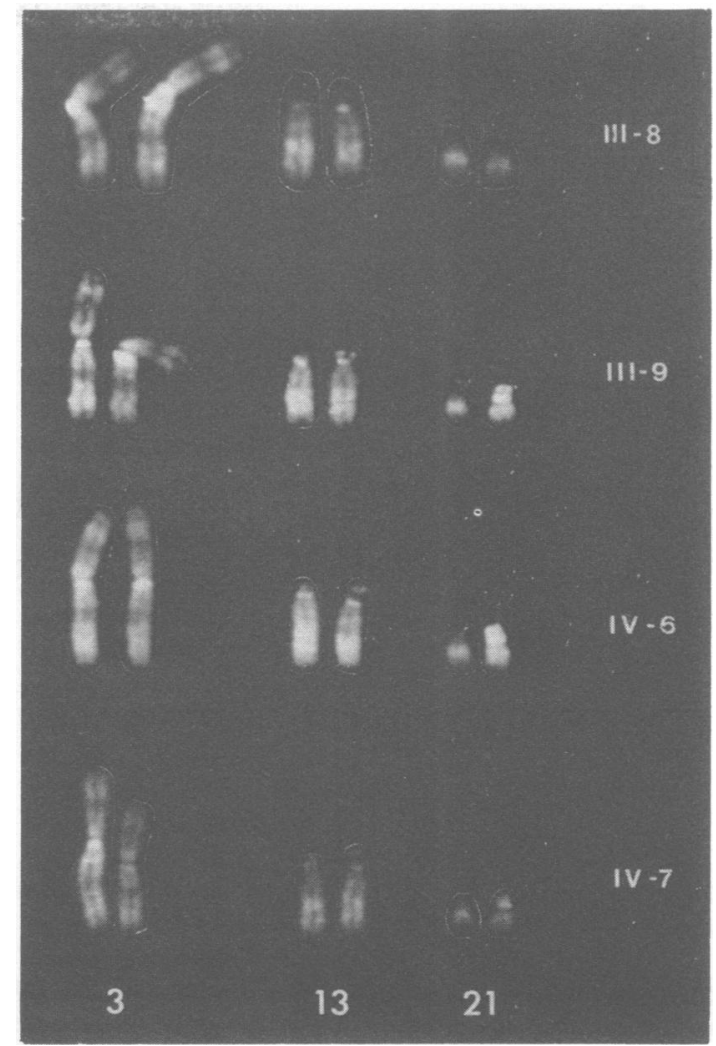

Fig. 6 Composite partial karyotypes of proband's mother (III.8, balanced carrier of the rearrangement); proband's father (III.9, normal); proband (IV.6, monosomic for $13 q 21$ $\rightarrow q 22)$; and proband's brother (IV.7, trisomic for $13 q 21 \rightarrow$ q22).

is approximately a fourth of the total length of band q21. Replication studies with BUDR-FPG technique have also shown these to be 2 late replicating bands separated by an earlier replicating band (B. S. Emanuel, 1977, personal communication). The diagrammatic representation of the rearrangement (Fig. 7) incorporates these observations. The break point in band q21 is interpreted as being in the light regions between the two sub-bands of band q21. The narrow bright band seen closely opposed to band $\mathrm{q} 31$ in the deleted chromosome 13 is the proximal sub-band of q21. This interpretation is consistent with the observation that both radiation-induced (Seabright, 1973) and spontaneous chromosome breaks (Jacobs et al. . 1974) are preferentially localised in the light band areas. The rearrangement is unlikely to cause any distortions of meiotic segregation, as the inserted interstitial segment is small.

Noel et al. (1976) have reported an adolescent girl with a deletion of the middle third of the long arm of 

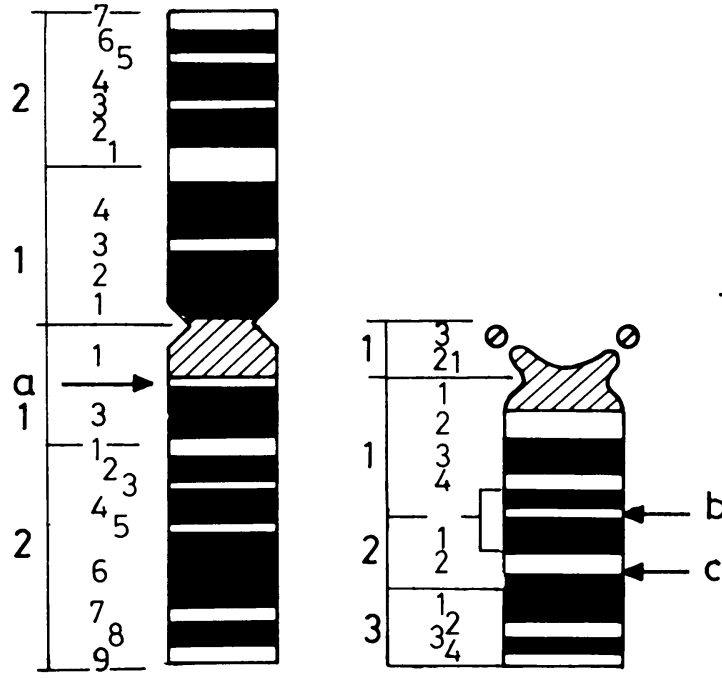

\section{3}

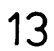

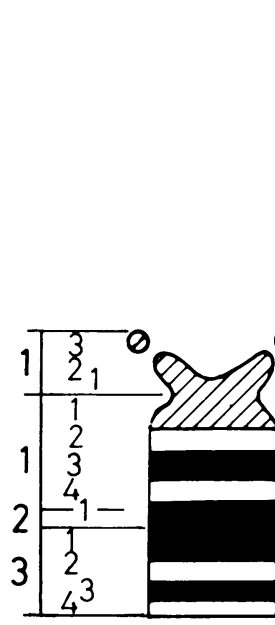

$13 q^{-}$

Fig. 7 Schematic diagram indicating break points in chromosome 3 and 13, showing the banding patterns of the 2 derivecos chromosomes $3 q+$ and $13 q-$.

chromosome 13 between bands q21 and q31. As far as the authors are aware, this is the only other case reported with deletion of this specific chromosome segment. The clinical features associated with the trisomic and monosomic states of this chromosome segment are summarised in the Table. Microcephaly, dystopia canthorum, strabismus, wide down-turning mouth, growth delay, mental retardation, and speech abnormalities were present in the 2 individuals monosomic for the segment in the present family and in the patient of Noel. In addition, the 2 members of ouro family had high arched palates and proximally inserted thumbs. The individuals trisomic for the $\overrightarrow{\overrightarrow{0}}$ segment were of normal mentality and only mildly 3 dysmorphic, with a high arched palate being their only? common feature.

Table Comparison of clinical features of patients monosomic and trisomic for chromosome segment $(13)(q 21 \rightarrow 22)$

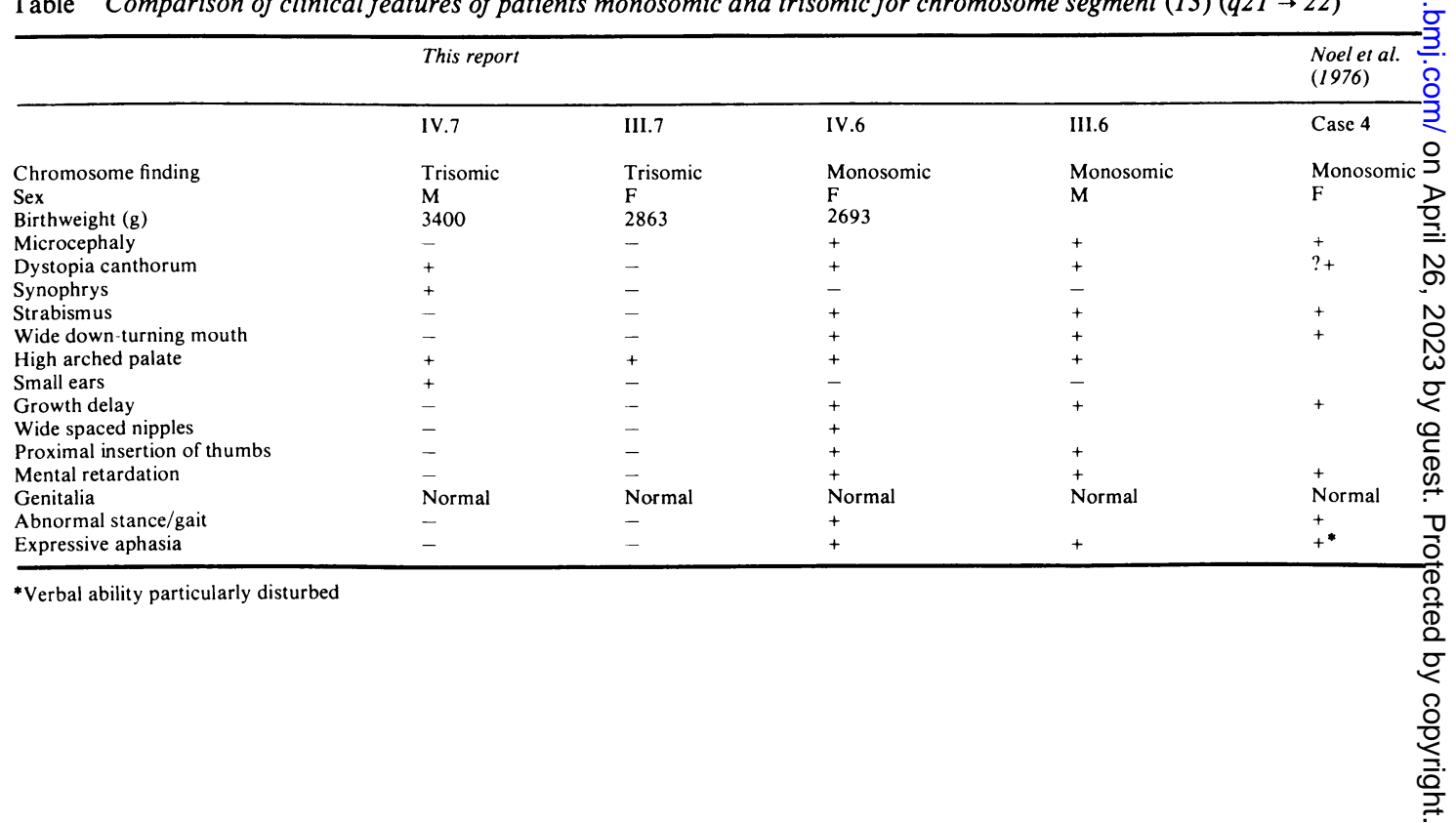


There does not appear to be evidence to support the 'le contretype' theory of LeJeune (1966) in the family presented here. Of those features for which 'opposites' might exist, such as mouth size, ear size, head circumference, thumb position, etc., the individuals monosomic and trisomic for the segment do not show contrasting variation. The segment involved in the translocation is composed primarily of heterochromatin with only a small amount of euchromatin. As suggested by Hoehn (1975) these areas when present in excess, or deleted from the chromosome complement, seem to be associated with less deleterious phenotypic effects, implying that a lesser amount of genetically relevant information is located in these areas.

Bilateral retinoblastoma associated with a 13q deletion has been reported in several cases. There is no evidence of retinoblastoma in our patient, nor in Noel's report. This is consistent with the finding that the deleted segment common to cases of retinoblastoma is band q14 of chromosome 13 (Francke, 1976; Knudson et al., 1976).

\section{References}

Berger, R., Touati, G., and Derre, J. (1974). 'Cri du chat' syndrome with maternal insertional translocation. Clinical Genetics, 5, 428432.

Caspersson, T., Zech, L., and Johansson, C. (1970). Differential binding of alkylating fluorochromes in human chromosomes. Experimental Cell Research, 60, 315-319.

Chudley, A. E., Bauder, F., Ray, M., McAlpine, P. J., Pena, S. D. J., and Hamerton, J. L. (1974). Familial mental retardation in a family with an inherited chromosome rearrangement. Journal of Medical Genetics, 11, 353-362.

Francke, U. (1976). Retinoblastoma and chromosome 13. Birth
Defects: Original Article Series, 12, No. 7, 131-134. The National Foundation-March of Dimes, New York.

Grace, E., Sutherland, G. R., and Bain, A. D. (1972). Familial insertional translocation. Lancet, 2, 231.

Gray, J. E., Syrett, J. E., and Ritchie, K. M. (1972). An interstitial translocation chromosome, no. Ip to 4q. Lancet, 2, 92-93.

Hoehn, H. (1975). Annotation. Functional implications of differential chromosome banding. American Journal of Human Genetics, 27, 676-686.

Jacobs, P. A., Buckton, K. E., Cunningham, C., and Newton, M. (1974). An analysis of break points of structural rearrangements in man. Annals of Human Genetics, 11, 50-64.

Knudson, A. G., Meadows, A. T., Nichols, W. W., and Hill, R. (1976). Chromosome deletion and retinoblastoma. New England Journal of Medicine, 295, 1120-1123.

LeJeune, J. (1966). Type et contretypes. Journées Parisiennes de Pediatrie, pp. 78-83. Cited in Warren, R. J., Rimoin, D. L., and Summitt, R. L. (1973). Identification by fluorescent microscopy of the abnormal chromosomes associated with the G-deletion syndromes. American Journal of Human Genetics, 25, 77-81.

Noel, B., Quack, B., and Rethoré, M. O. (1976). Partial deletions and trisomies of chromosome 13; mapping of bands associated with particular malformations. Clinical Genetics, 9, 593-602.

Paris Conference (1971). Standardization in human cytogenetics. Birth Defects: Original Article Series, 8, No. 7, 1972. The National Foundation-March of Dimes, New York.

Rethoré, M. O., LeJeune, J., Carpentier, S., Prieur, M., Dutrillaux, B., Sevinge, P. H., Rossier, A., and Job, J. C., (1972). Trisomie pour la partie distale du bras court du chromosome 3 chez trois germains. Annales de Génétique, 15, 159-165.

Seabright, M. (1973). High resolution studies of the pattern of induced exchanges in the human karyotype. Chromosome, 40, 333-346.

Shapiro, L. R., and Warburton, D. (1972). Interstitial translocation in man. Lancet, 2, 712-713.

Requests for reprints to Dr K. E. Toomey, Department of Pediatrics, College of Medicine, University of South Florida, Box 15, 12901 North 30th Street, Tampa, Florida 33612, USA. 